\title{
El catálogo de Pijao Editores (1972-2000): UNA EDITORIAL "ALTERNATIVA"*
}

\author{
The catalog of Pijao Editores (i972-2000): \\ an "Alternative” Publishing House
}

\author{
Paula Andrea Marín Colorado ${ }^{1}$
}

\begin{abstract}
* Artículo de investigación derivado del proyecto "La edición del cuento colombiano en el siglo xx, Poéticas y soportes", desarrollado en el marco del grupo de investigación Colombia: tradiciones de la palabra (Universidad de Antioquia), con el apoyo del Fondo Nacional de Financiamiento para la Ciencia, la Tecnología y la Innovación "Francisco José de Caldas" (colciencias). Asimismo, se inscribe en la Estrategia de Sostenibilidad para grupos de investigación Universidad de Antioquia, UdeA 2018-2019.
\end{abstract}

Cómo citar este artículo: Marín Colorado, $\mathrm{P}$. (2019). El catálogo de Pijao Editores (19722000): una editorial "alternativa". Estudios de Literatura Colombiana 46, pp. 177-194. DOI: https://doi.org/10.17533/udea.elc.n46a09

1 https://orcid.org/0000-0002-9930-4500 paulanmc@gmail.com

Universidad de Antioquia, Colombia

Editores: Andrés Vergara Aguirre, Christian Benavides Martínes, Vanessa Zuleta Quintero

Recibido: 15.08 .2019

Aprobado: 21.10 .2019

Publicado: 27.12.2019

Copyright: (2020 Estudios de Literatura Colombiana. Este es un artículo de acceso abierto distribuido bajo los términos de la Licencia Creative Commons AtribuciónNo comercial - Compartir igual 4.0 Internacional
Resumen: desde el enfoque de los estudios editoriales, aquí se reconstruye parte de la historia de Pijao Editores (1972-actual), una de las editoriales literarias colombianas de más larga trayectoria en el país, reconocida por su robusto catálogo literario y por haber funcionado como casa de difusión de las primeras obras de muchos autores colombianos, en un momento en el que no encontraban fácilmente apoyo para la publicación de sus obras. Los objetivos del texto son presentar una parte de la historia - hasta hoy inexistente- de la editorial y reconstruir y analizar su catálogo (1972-2000).

Palabras clave: edición; industria del libro; colección de libros; literatura latinoamericana.

\begin{abstract}
From the focus of the editorial studies, in this text, I will reconstruct part of the history of the publishing house Pijao Editores (1972-present), one of the longest-running Colombian literary publishers in the country. Pijao Editores is recognized for its robust literary catalog and for functioning as a publishing house for the dissemination of the first works of many Colombian authors, when they did not easily find support for the publication of their works. The objectives of the text are, on one hand, to present a part of the history - until now non-existent - of the publishing house and, on the other hand, to reconstruct and analyze its catalog (1972-2000).
\end{abstract}

Keywords: edition; book industry; books collection; Latin American literature. 


\section{La circulación del libro en Colombia (1970-2000)}

El período 1970-1990 representa un crecimiento y diversificación del mercado editorial local debido, sobre todo, a la aparición de varias editoriales nacionales. Entre 1971 y 1989, el número de títulos publicados pasó de 628 a 9000 (Arango, 1991, p. 27), con temas diferentes a los ya tradicionales mercados de las publicaciones periódicas, el libro escolar, el libro religioso y el legislativo. Este breve auge "abrió espacios de publicación a autores nacionales que antes difícilmente podían encontrar una editorial que se arriesgara a publicarlos y contribuyó al aumento y consolidación del público lector"(Marín Colorado y Valencia, 2018, p. 169), que siguió siendo, sin embargo, bastante pequeño.

Dicho auge editorial tiene varios antecedentes: la creación del cERLALC en 1971, en Bogotá; la aprobación de la Ley del Libro en 1973 (actualizada en 1983 y en 1993); la ampliación de la red de bibliotecas públicas del país; la promulgación de una nueva ley de propiedad intelectual en 1982; los enormes tirajes y ventas de los libros de Gabriel García Márquez, y "la aparición de las primeras facultades de Diseño Gráfico, cuyos egresados aportaron a la modernización del diseño editorial” (Marín Colorado y Valencia, 2018, p. 169). El antecedente más sobresaliente, no obstante, es la notable disminución de la tasa de analfabetismo, que pasó de más del $40 \%$ a mediados del siglo xx (Silva, 2012, p. 218), al 6,8\% en territorio urbano y 23,6\% en territorio rural en 1985; el aumento de la población alfabetizada fue un proceso que coincidió con el crecimiento de la población universitaria y la consolidación de una clase media en el país. A inicios de la década de 1980, la industria editorial pudo aprovechar la inversión que se había hecho desde algunas décadas atrás en tecnologías, insumos y maquinarias de impresión (Marín Colorado, 2018, p. 386).

Los libros que circulaban en el país provenían, en su mayoría, de España y de Argentina. Pero, a partir de 1970, los colombianos comenzaron a ver más libros producidos en el país en las vitrinas de las librerías — que seguían y siguen siendo muy pocas - y también en almacenes de cadena, farmacias y semáforos. "En la segunda mitad de la década de 1980 el número de libros exportados superó (por primera vez) al de los importados" (Marín Colorado y Valencia, 2018, p. 170).

Desde finales de la década de 1980 y durante la de 1990, las editoriales españolas en Colombia recobraron el mercado de textos escolares y de interés general, pero en 
sus catálogos ya no figuraban autores nacionales, como sí lo habían hecho en décadas anteriores en los de Plaza \& Janés y Planeta. Esta "reconquista” por parte del mercado editorial español, junto con el ingreso de China al mercado de impresión en la década de 1990, marcó el fin del apogeo de la industria gráfica colombiana. A los hechos mencionados se sumó también "el escándalo provocado por el aprovechamiento ilícito de los privilegios cambiarios para los exportadores, que desembocó en la disminución de estímulos fiscales" (Marín Colorado y Valencia, 2018, p. 171), así como también la distorsión del mercado que provocaron los tirajes de los libros de García Márquez y la posterior pérdida de los derechos de publicación de sus obras en el país, por cuenta de la acusación de piratería contra La Oveja Negra (Marín Colorado, 2018, p. 393).

\section{Pijao Editores (PE): Una "fuerza alternativa"}

"Seguiremos publicando libros que las grandes editoriales no pueden divulgar por su aparente poco interés comercial". ${ }^{\mathrm{I}}$

La década de 1960 en Colombia (y en América Latina) estuvo caracterizada por la radicalización de los movimientos sociales y políticos de izquierda, inspirada por la Revolución cubana y por el Mayo del 68 francés. A finales de esta década, intelectuales antioqueños (muchos de ellos, profesores universitarios) fundaron editoriales con una clara tendencia de izquierda (La Oveja Negra, La Carreta, El Tigre de Papel, Zeta, La Pulga, Estrategia, Hombre Nuevo, Ocho de Junio, Norman Bethune y Pepe), las cuales fueron responsables de lo que acabó convirtiéndose en el auge del "libro de izquierda" (Gómez García, 2005, p. 62), “impulsado y sostenido por los estudiantes universitarios, los sindicalistas y los militantes y simpatizantes de la izquierda" (Marín Colorado y Valencia, 2018, p. 173). El libro de izquierda preparó, de esta manera, un espacio para la circulación del libro colombiano (de autores colombianos y sobre temas colombianos).

En este contexto también se debe incluir la fundación de PE, en la ciudad de Ibagué (capital del departamento del Tolima), en 1972. Los hermanos Carlos Orlando y Jorge Eliécer Pardo Rodríguez publicaron el libro de cuentos de su autoría

1 Texto de la contrasolapa del libro Mangle adentro, de Cesáreo Rocha (1992), publicado por Pijao Editores. 
Las primeras palabras con recursos propios, ${ }^{2}$ derivados de sus salarios como maestros —entonces Normalistas - de escuela, y con los aportes de sus familiares. ${ }^{3}$ El libro fue presentado en el hotel Ambalá de Ibagué y contó con la presencia del decano de la Facultad de Educación de la Universidad del Tolima. Se imprimieron 3000 ejemplares que se vendieron rápidamente, sin haber sido distribuidos en librerías. Germán Vargas Cantillo y Fernando Soto Aparicio comentaron positivamente el libro en los suplementos literarios más importantes de la época (figura 1).

Este libro dio inicio a las actividades de una editorial que, hasta hoy, ha tenido como objetivo la publicación de autores colombianos, sobre todo tolimenses, para quienes es difícil acceder a editoriales corporativas o comerciales. De allí que el logo de la editorial — que se mantiene con pocas variaciones hasta hoy-, diseñado por Álvaro Hernández (figura 2), sea un arco con una flecha que parece disparar al revés, como expresión de una actitud de ir siempre en contravía. Pero también el logo escogido como sello editorial hace referencia a "lo que más representa la tierra": los indígenas pijaos, habitantes del Tolima y de los territorios aledaños, desde antes de la llegada de los españoles. La historia los resalta como un pueblo "belicoso", descendiente de los caribes, que se resistió a la colonización española por muchos años, tras los cuales fueron aniquilados, sin nunca haberse rendido, tal como lo han hecho hasta hoy los hermanos Pardo, al seguir manteniendo en pie su proyecto editorial, a pesar de todas los obstáculos para publicar y distribuir libros en Colombia (C. O. Pardo, 2018).

2 Carlos Orlando Pardo Rodríguez (Líbano, Tolima, 1947). Novelista, cuentista y poeta. Normalista y Licenciado en Ciencias de la Educación de la Universidad Pedagógica Nacional. Fue profesor de literatura en escuelas y colegios, y periodista cultural de radio y televisión. También fue Secretario de Educación del Tolima y director del Instituto Tolimense de Cultura (cuya creación impulsó). Durante sus administraciones, llevó a cabo una exitosa campaña de alfabetización que luego fue replicada por el Gobierno nacional (la campaña Simón Bolívar) y fundó 14 bibliotecas municipales; también fue el director de la colección Biblioteca de Autores Tolimenses e instauró el Premio Tolimense de Literatura y el Premio Tolimense de Periodismo, otorgados en distintas versiones a Eutiquio Leal, Eduardo Santa, Héctor Sánchez, Policarpo Varón, C. O y J. E. Pardo y Germán Santamaría.

Jorge Eliécer Pardo Rodríguez (Líbano, Tolima, 1950). Novelista, cuentista y poeta. Normalista y Licenciado en Español e Inglés de la Universidad del Tolima. Doctor en Literatura por la Universidad Javeriana. Especialización en Administración Pública (Esap). Ha ejercido como periodista cultural de radio y televisión, funcionario público y como profesor de literatura en colegios y universidades. Sus más recientes premios son el x Premio Nacional de Literatura (elegido por los lectores de la Fundación Cultural-revista Libros y Letras, en 2013) y el de la xvi Bienal Internacional de Novela José Eustasio Rivera (Fundación Tierra de Promisión-Secretaría de Cultura de Neiva, 2018), por Maritza la fugitiva, que hace parte de su proyecto narrativo "El quinteto de la frágil memoria".

3 Sus padres trabajaban en el comercio de muebles y en el negocio del transporte público; su tía: Sofía Rodríguez de Moreno — personaje muy importante durante la niñez de los hermanos Pardo—, había fundado en 1962, junto a su esposo, la Academia de Arte y Teatrino Don Eloy, en Bogotá. 
Fuente: tomada de un ejemplar de Las primeras palabras (Carlos Orlando Pardo R. y Jorge Eliécer Pardo R.). Biblioteca Luis Ángel Arango (BLAA), Bogotá. por PE (1972).

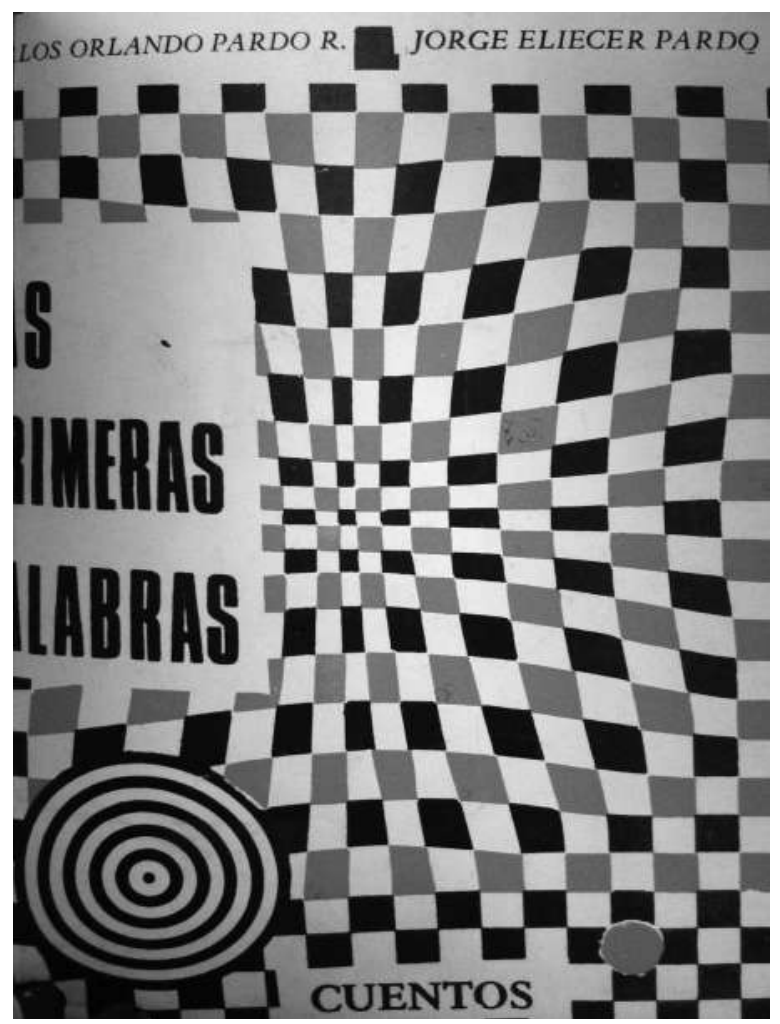

Figura 1. Carátula diseñada por John de Greck del primer libro p ublicado

Fuente: tomado de la contracarátula de un ejemplar de ${ }_{i} M a r i l y n ?$ ? (Germán Santamaría), tercer libro de cuentos publicado por la editorial. BLAA, Bogotá.

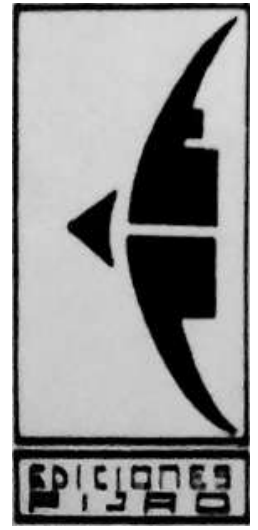

Figura 2. Sello de Pijao Editores en 1974. 
En 1989, al cumplirse 17 años de la fundación de PE, los hermanos Pardo Rodríguez se referían a la labor realizada con estas palabras, publicadas en la revista Pijao (fundada también por los Pardo en 1978):

\begin{abstract}
En algunos círculos se debate el hecho soterradamente, de que la literatura se desarrolle y dé a conocer en la provincia, por ese falso prurito de cosmopolitismo, que nada tiene que ver con ser o vivir en la capital del país. [...] Las pequeñas editoriales, sin capital económico, sin publicidad en los medios masivos, sin reconocimiento de críticos y reseñadores, van adquiriendo presencia en la historia de nuestra cultura. El problema de la distribución, la forma como el libro logra el estante de la librería, el pago de los libreros, son escollos que aún no hemos podido solucionar. Pero los textos de estas pequeñas editoriales, van por las bibliotecas escolares, universitarias, de los colegios, llenan las incipientes bibliotecas de los pueblos y son referencia de las clases de literatura de los jóvenes profesores de español que hallan en ellos un material de una realidad contemporánea y unas formas distintas a las caducas estructuras novelísticas del siglo pasado.

$\mathrm{Y}$, estas pequeñas editoriales, no tienen el más vendido [...], ni adornan las vitrinas, pero sí están reseñados en los estudios de profesores norteamericanos y europeos (Pijao, 1989, p. 19).
\end{abstract}

La cita anterior sintetiza la política editorial de PE: publicar autores, sobre todo, del Tolima, que tienen pocas oportunidades de publicar sus obras en editoriales con capital económico, simbólico o cultural, y reconocimiento en los medios de comunicación, por lo general, con sede en la capital del país; es decir, su finalidad es presentarse como una "fuerza alternativa" para los escritores de su región y del país (C. O. Pardo, 2018). Los hermanos Pardo reconocían y reconocen las dificultades que representa mantener una editorial en estas condiciones, sobre todo en lo relacionado con los mecanismos de distribución-circulación, difusión y recepción de sus libros. Aunque estas dificultades no son solo de PE, sino de todas las editoriales pequeñas y, más aún, las regionales, cada una de ellas encuentra maneras de superarlas; en el caso de PE, se han encargado ellos mismos de hacer la distribución y han recurrido a sus contactos en periódicos de circulación nacional y local para difundir sus títulos — aunque esto es cada vez más difícil—. Además de ello, han recurrido a dos vías de las que han obtenido mayores beneficios: el circuito escolar y la academia literaria. 
Los hermanos Pardo, así como muchos de sus colegas, maestros de escuelas y colegios, como ellos — que no pertenecían a familias de tradición intelectual o letrada en el país-, pero también periodistas, abogados y publicistas, elaboraban sus obras literarias en la sombra. Dos redes de sociabilidad contribuyeron enormemente a la consolidación de lo que los Pardo y varios escritores contemporáneos denominan el Grupo Pijao: el grupo de teatro dirigido por el escritor Héctor Sánchez y el taller literario dirigido también por él (en la Universidad del Tolima, Ibagué), inspirados por el taller que había dirigido Eutiquio Leal en Cartagena. Además de los intereses literarios y artísticos, quienes se reunían alrededor de estas actividades eran líderes sindicales, activistas políticos o estaban afiliados a alguna asociación sindical, influidos por los movimientos sociales y políticos de izquierda de la época. Los intereses literarios y la preocupación social y política por contribuir al cambio del país consolidaron un grupo (de 30 personas aproximadamente) que, luego de la diseminación de los grupos de teatro y del taller literario, siguió reuniéndose en casa de los hermanos Pardo para compartir lecturas y leer sus obras (y luego publicarlas).

Las bibliotecas de las escuelas y colegios en los que la mayoría de los integrantes del Grupo trabajaban como maestros tenían un acervo desactualizado y fueron los libros de PE los que contribuyeron a renovar la literatura colombiana que podían trabajar con sus estudiantes durante las clases y que les hablaba de muchas de las situaciones que vivían en ese momento, en un lenguaje familiar y en un paisaje que podían sentir como propio. Otro de los miembros del Grupo: Humberto Tafur, se había dedicado por muchos años a viajar por las provincias vendiendo libros por catálogo de las editoriales colombianas y extranjeras; muchos de los integrantes del Grupo Pijao eran sus clientes. Eran escritores cuyas primeras lecturas no habían sido los clásicos de la literatura colombiana ni "universal", sino las obras de los autores del boom de la literatura latinoamericana (J. E. Pardo, 2018).

La lectura de los autores del boom los puso frente a una situación: ¿cómo ser reconocidos como escritores desde la provincia, sin tener que irse a vivir a la capital del país o a París o a Barcelona? En otras palabras, ¿cómo asumirse como escritor desde la provincia sin necesitar de la legitimación literaria capitalina? Existen relaciones de fuerza-dominación entre países por el prestigio literario, tal como lo ha planteado Pascale Casanova (2001) con el funcionamiento de la "geopolítica literaria”: "Formada 
por la oposición entre una capital literaria (universal) y regiones que dependen de ella” (p. 24), por relaciones de dominación (político-lingüístico-cultural) entre los países “más dotados" y los “menos dotados" literariamente. Estas relaciones de fuerzadominación literaria se reproducen a nivel intranacional en las tensiones entre capital y provincia, entre centro y periferia — donde el centro es, por lo general, la expresión de la "modernidad", y la provincia, la del "anacronismo"-. En el caso del campo literario colombiano, el examen de estas relaciones es imprescindible, pues la tensión entre las diferentes regiones del país ha estado presente desde la Colonia y es una característica insoslayable de la cultura colombiana (Tirado Mejía, 1983, p. 45).

Los hermanos Pardo han asumido esta tensión buscando la legitimación de sus obras y la de varios de los autores de PE (los más cercanos al Grupo Pijao: Héctor Sánchez, Benhur Sánchez, Humberto Tafur, Eutiquio Leal, Germán Santamaría, Eduardo Santa), a través de instancias de consagración (Dubois, 2014, p. 74) literarias (academias, premios, cooptaciones) nacionales y, sobre todo, internacionales. ${ }^{4}$ Ante la falta de instancias de reconocimiento literario (crítica literaria, reseñas en la prensa y en otros medios de comunicación) que se ocupen de visibilizar los títulos y autores publicados por PE en Colombia, los Pardo - y, sobre todo, Carlos Orlandohan asumido la tarea de llamar la atención de la academia universitaria literaria colombiana, estadounidense y francesa para lograr su legitimación como escritores. De allí que Carlos Orlando y Jorge Eliécer hayan logrado traducir algunas de sus novelas al francés (por Jacques Gilard) y al inglés; también que en 2019 prepararan el Encuentro de Nuevos Colombianistas, en el que presentaron el primer título de su Colección Crítica Literaria: un libro de uno de los fundadores de la Asociación de Colombianistas en Estados Unidos (Raymond Williams) sobre la novela del Gran Tolima. Este libro se entiende como un nuevo capítulo del ya clásico libro de Williams: Novela y poder en Colombia (1991), dedicado a la novela del Gran Cauca, de Antioquia, la Costa Caribe y el Altiplano cundiboyacense.

Esta ha sido la manera en la que los hermanos Pardo han contribuido a equilibrar — aunque nunca del todo— las fuertes relaciones de dominación literaria

4 Jacques Dubois (2014, p. 74) plantea que la institución literaria actúa a partir de la interacción de diferentes instancias, cuya función es elaborar, definir y legitimar las obras literarias; esas instancias son de emergencia (salones, revistas), de reconocimiento (crítica-prensa), de consagración (academias, premios, cooptaciones) y de canonización (programas y manuales de las instituciones educativas). 
entre la capital del país y las provincias, en este caso entre Bogotá y el departamento del Tolima; de esta manera, han logrado el reconocimiento y la validación de varios escritores del Tolima dentro del campo literario colombiano, como antes ya lo habían hecho los escritores de Antioquia y de la Costa Caribe, a través de los trabajos de Tomás Carrasquilla a principios del siglo xx y del denominado Grupo de Barranquilla hacía tan solo una década.

En últimas, lo que han hecho los hermanos Pardo por contribuir al reconocimiento de sus obras y las de los escritores más cercanos al Grupo Pijao no es una práctica extraña en la vida literaria de cualquier parte: para los críticos literarios, reseñistas, editores o investigadores es imposible conocer todo el corpus de una literatura (regional, nacional o extranjera), y sus referencias siempre hacen parte del repertorio de su red de sociabilidad más cercana; en ella se consultan los nombres de los autores y de las obras que "valen la pena", se "trafican" referentes y prestigios. Por ello es tan importante para cualquier escritor contar con una red de sociabilidad fuerte, con un capital social que le represente una red de contactos que pueda contribuir a hacer visible su figura y su obra (en publicaciones periódicas, en editoriales, en eventos literarios, en concursos) (Sapiro, 2016, p. 47). Es ese capital social el que han construido los hermanos Pardo, a través del Grupo Pijao y de su participación activa en la vida cultural y política del Tolima, como funcionarios públicos de la Contraloría (Jorge Eliécer), y de la Secretaría de Educación y del Instituto Tolimense de Cultura (Carlos Orlando), pero también como organizadores del I Encuentro Nacional por la Literatura en 1980 (con la participación de más de 200 escritores colombianos) y como miembros fundadores de la Unión Nacional de Escritores (UNE) en 1981.

La vida (literaria) colombiana funciona sobre prejuicios que han sido alimentados desde el siglo xix y que reproducen prácticas de exclusión. Uno de ellos es el de la "gente de tierra caliente", etiqueta con la que los bogotanos se refieren a las personas oriundas de regiones cuyos pisos térmicos están por debajo de los 1000 m.s.n.m., como es visible en novelas como Manuela (Eugenio Díaz, 1858) y Tránsito (Luis Segundo de Silvestre, 1886). En dos de los prólogos (uno escrito por Carlos Orlando Pardo y el otro por Germán Vargas Cantillo) de los libros de pe publicados en la década de 1970, los autores se refieren a este prejuicio que recae sobre la gente del Tolima: "Alguien dijo erradamente que del Tolima nunca saldría un buen escritor 
porque su gente era dada a la pereza y a la contemplación de la noche [...], influidos por el clima cálido que los llevaba a la quietud y el abandono" (Vargas Cantillo, 1976, p. 11). El prejuicio social se tradujo en uno literario que obstaculiza(ba) el reconocimiento y la valoración las obras de los escritores de una región del país, como ya había sucedido con los antioqueños y con los costeños. Ante esto, los Pardo fundan una editorial para "desbloquear" a los autores regionales y hacerlos visibles en el panorama nacional.

PE ha sido sostenida con parte de los salarios de los hermanos Pardo como profesores y como funcionarios públicos, con préstamos a familiares y a bancos, y, en su etapa más reciente, con parte de la pensión de Carlos Orlando Pardo y con parte de los dividendos de un negocio del que fue su fundador. En su primera década, también fue muy importante para la editorial el patrocinio de instituciones como el Fondo Cultural de Beneficencia del Tolima, la Secretaría de Educación y Cultura del Tolima, el Fondo Mixto para la Promoción de la Cultura y las Artes del Departamento del Tolima, la Gobernación del Departamento del Tolima y el Fondo Rotatorio de Publicaciones y Cultura de la Contraloría General del Tolima. Este modo de funcionamiento les ha permitido pagar derechos de autor, sin jamás cobrarle a ningún escritor por la publicación de su libro. De esta forma, los hermanos Pardo asumen su papel como editores en un sentido integral: desde la responsabilidad en la selección de los títulos que publican (111 de ellos en el marco de una colección) hasta la distribución de los libros y la promoción de sus autores. En este sentido, PE no es una empresa comercial, sino un proyecto cultural (y familiar) que, aunque no representa ganancias económicas para sus fundadores (C. O. Pardo, 2018), sí les ha permitido aportar a la transformación del campo editorial colombiano, diversificando la oferta editorial y haciendo visibles a más escritores.

\section{El catálogo de PE}

El catálogo de PE es un catálogo mayoritariamente literario, decisión claramente derivada de los intereses de los hermanos Pardo Rodríguez. En la última década, la editorial ha tenido dos hitos: la publicación de la colección 50 Novelas Colombianas, en 2008, y la coedición con el grupo editorial español Sial Pigmalión (en 2017), 
que ha significado la internacionalización editorial del sello colombiano; el primero de ellos se logró en coedición con Caza de Libros, la editorial (también de Ibagué) de Pablo Pardo Rodríguez (uno de los ocho hermanos de Carlos Orlando y Jorge Eliécer), en cuyos talleres hoy imprime PE.

No existe un catálogo completo de la editorial. El único al que se puede acceder se limita a los libros (en formato impreso y e-book) que aparecen en su página web (http://pijaoeditores.com/) y que han sido publicados entre 2014 y 2018. A pesar de que en todos los artículos de prensa que se han publicado sobre la editorial, los hermanos Pardo aseguran que su catálogo tiene más de 600 títulos, el que he podido reconstruir, a partir de la revisión de los catálogos de la Biblioteca Nacional, la Biblioteca Luis Ángel Arango y Worldcat, cuenta con 211; los libros que aparecen en la página web suman 88 títulos, para un total de 299. ¿Dónde están los otros más de 300 ?

De los libros revisados en físico en las Bibliotecas Luis Ángel Arango (sedes de Bogotá y de Ibagué) y en la Biblioteca Nacional de Colombia, la mayoría no cuenta con número IsBN. Los hermanos Pardo afirman que durante muchos años fueron "descuidados" con los procesos más formales de la editorial y que no conservan archivos o ejemplares de todos los títulos publicados; tampoco hicieron depósito legal de manera sistemática. El incumplimiento de estos requisitos técnicos ocasionó el hecho de que muchas bibliotecas no incluyeran los libros de PE en sus compras (J. E. Pardo, 2018). Esta sería una de las causas por las cuales los libros no se encuentran en las bibliotecas consultadas para esta investigación. Por otro lado, la numeración de los libros que se encuentran dentro de colecciones (Autores Nacionales, Biblioteca de Autores Tolimenses, Obra Selecta, Vida y Obra, Testigo, Narradores de Hoy, Maestros Contemporáneos, Obra Literaria, Libros de Bolsillo, Lecturas Juveniles Selectas) es errática y no me fue posible reconstruirlas en su totalidad.

Dentro de este panorama de informalidad editorial cabría también conjeturar que la cifra estimada por los fundadores de PE no es real. A lo anterior se suma el hecho de que para 1989 hubieran publicado 50 títulos (Ortiz Vidales, 1989, p. 25), es decir, en promedio, 3 títulos al año, aun cuando fue el año 1986 uno de los momentos de mayor publicación de la editorial. Así las cosas, no sería descabellado pensar que los 299 títulos sean un número muy aproximado a la realidad de publicación de PE, 
una empresa no comercial, sino cultural, que no constituye la actividad económica principal de sus fundadores.

De los 211 títulos revisados en bibliotecas, 159 corresponden a obras literarias (ver tabla 1$)$ :

Tabla 1. Catálogo de PE por temas.

Fuente: Elaboración propia.

\begin{tabular}{|c|c|}
\hline Temas & Número de títulos \\
\hline Novela & 81 \\
\hline Cuento & 44 \\
\hline Poesía & 26 \\
\hline Literatura juvenil & 6 \\
\hline Teatro & 2 \\
\hline Ensayo & 14 \\
\hline Historia & 14 \\
\hline Biografía & 11 \\
\hline Diccionarios de autores & 2 \\
\hline Crónica & 4 \\
\hline Testimonio & 2 \\
\hline Enciclopedia & 1 \\
\hline Educación & 2 \\
\hline Fotografia & 1 \\
\hline Espiritualidad & 1 \\
\hline Total & 211 \\
\hline
\end{tabular}

Después de la literatura, el otro gran interés de PE ha sido recoger la historia del Tolima, incluyendo la de su música, pintura y autores literarios, a través de diccionarios de autores y de varios títulos dedicados a la vida y obra de algunos de los escritores del Grupo Pijao (Héctor Sánchez, Eutiquio Leal y Eduardo Santa). La intención de Carlos Orlando Pardo, quien ha estado al frente de estos proyectos, es incluir a todos los que hayan aportado a la construcción cultural del Tolima.

En la década de 1990 aparece la literatura infantil en el catálogo de PE, cuando esta línea ya había alcanzado cierta consolidación en el espacio editorial colombiano (Marín 
Colorado, 2018, p. 403); también es el momento en el que los libros pasan a ser impresos en papel bond (antes lo eran en papel prensa) y es la década de mayor publicación de la editorial (descontando el hito de la Colección 50 Novelas Colombianas, en 2008). Los libros de $\mathrm{PE}$ tienen en promedio menos de 300 páginas, presentan encuadernación en rústica, la mayoría de ellos con ilustración a color en la cubierta. El tiraje en los comienzos de la editorial y hasta la década del 2000 fue de 2000 a 3000 ejemplares; en la etapa más reciente de la editorial, este va de 500 a 1000 ejemplares, en concordancia con la tendencia nacional, regional y mundial de disminución de los tirajes. ${ }^{5}$ Las críticas frente a la materialidad de los libros de PE durante la década de 1980 no fueron pocas y se concentraban en señalar el hecho de que, así una edición pretendiera ser económica, no podía descuidar aspectos como la composición de los colores en las cubiertas, los criterios tipográficos de unificación, la redacción, las pautas de diagramación, fotomecánica e impresión (Torres Duque, 1990, p. 104).

El equipo de trabajo de PE (con sede en la casa de Carlos Orlando Pardo,en Ibagué), además de los hermanos Pardo, estuvo conformado por dos diseñadores, un corrector de estilo y un corrector de pruebas. ${ }^{6}$ Hoy, el equipo lo conforman un encargado de las comunicaciones de la editorial (página web, redes sociales), una persona encargada de la distribución de los libros desde Bogotá (para la capital del país, Medellín, Cartagena, Barranquilla, Cali y Pereira) y otra persona encargada de la corrección de los textos y de la diagramación: el también escritor e hijo de Carlos Orlando Pardo, Pablo Pardo Viña (C. O. Pardo, 2018). PE, como empresa familiar y proyecto cultural, ha tenido como objetivo fundamental, más que profesionalizarse como empresa editorial comercial, servir de casa de publicación de los autores tolimenses y colombianos, y promocionar sus obras, comenzando por la de sus propios fundadores.

De lo anterior se deriva el hecho de que Carlos Orlando Pardo sea el autor con más títulos dentro del catálogo (nueve como compilador y 21 como autor de novelas, cuentos y poesía, además de ensayos y biografías), al que le siguen su hermano Jorge Eliécer (12 títulos como autor de novelas, cuentos, poesía y una biografía), Héctor

5 La mayoría de los libros de PE carecen de datos de impresión. Los tamaños de los libros, en promedio, están entre los 18 x $10 \mathrm{~cm}$ y los 21 x $10 \mathrm{~cm}$.

6 Jorge Eliécer Pardo se fue a vivir a Bogotá hace 40 años; desde allí ha seguido colaborando con PE, pero afirma que, desde hace aproximadamente 10 años, está más dedicado a la publicación y promoción de su propia obra literaria, desde otras editoriales (J. E. Pardo, 2018). 
Sánchez (12 títulos como autor de novelas, cuentos y ensayo) y Benhur Sánchez (siete títulos como autor de novelas y cuentos). ${ }^{7}$ De los demás autores de PE, siete cuentan con tres títulos cada uno en el catálogo (Fernando Ayala Poveda, Camilo Pérez Salamanca, Eduardo Santa y Germán Vargas Cantillo entre ellos, para nombrar solamente a los autores de obras literarias); otros seis cuentan con dos títulos cada uno (Libardo Vargas, Humberto Tafur, Germán Santamaría y Álvaro Cerón entre ellos, para nombrar solamente a los autores de obras literarias); el resto de autores cuenta con un título en el catálogo, entre ellos las mujeres, que solo alcanzan los 20 títulos entre los 211 revisados. La primera autora publicada fue Sonia Nadhezda Truque, en 1986, con su primer libro de cuentos: La otra ventana.

De los 211 títulos revisados, 20 han tenido al menos una reedición en la editorial. Los autores más reeditados por PE son los escritores Carlos Orlando y Jorge Eliécer Pardo (sobre todo, sus novelas). Por su parte, las obras más reeditadas son dos novelas de Jorge Eliécer: Eljardín de las Weismann (con nueve ediciones, publicada por primera vez en Plaza \& Janés) e Irene (con siete ediciones, publicada por primera vez en PE). A estas le siguen: los libros de cuentos La violencia diez veces contada (compilación de Germán Vargas Cantillo), Un vestido rojo para bailar boleros (de Carmen Cecilia Suárez) y La octava puerta (de Jorge Eliécer Pardo, publicado por primera vez en La Oveja Negra), cada uno con tres ediciones (los dos primeros publicados por primera vez en PE); y las obras de Carlos Orlando Pardo: Lolita golondrinas (novela, publicada por primera vez en La Oveja Negra) y Poetas tolimenses (compilación, publicada por primera vez en PE), cada una con dos ediciones.

Por otra parte, de los 211 títulos revisados, 162 han sido publicados por primera vez en PE. De estos 162 títulos, siete aparecieron luego en otras editoriales (dos de ellos en Caza de Libros); de los 49 títulos restantes, publicados por primera vez en otra editorial, 8 han sido reeditados, después de su publicación en PE (uno de ellos en Caza de Libros). Esto quiere decir que 15 de los títulos de PE han sido luego publicados por otra editorial: 10 novelas, 3 libros de cuentos, uno de poesía y otro de ensayos; esas editoriales son (además de Caza de Libros): La Serpiente Emplumada, Arango Editores, Grijalbo, Olimpia, Taller de Edición Rocca, Gato Azul, Cangrejo Editores,

7 Estos mismos 4 autores configuran hoy la colección de PE Maestros Contemporáneos (http://pijaoeditores. com/tienda/coleccion/maestros-contemporaneos.html? $\mathrm{p}=1$ ). 
(Sic) Editorial y cinco editoriales universitarias. De los primeros siete títulos, el autor más reeditado en otras editoriales, después de su publicación en PE es Jorge Eliécer Pardo (tres títulos). Las obras más reeditadas en otras editoriales, después de su primera edición en PE, son: Un vestido rojo para bailar boleros (10 ediciones) y Trashumantes de la guerra (novela, con dos ediciones), de Jorge Eliécer Pardo; las obras más reeditadas que fueron publicadas por primera vez en otra editorial, antes de su paso por PE, son: Cóndores no entierran todos los días (novela, de Gustavo Álvarez Gardeazábal) y Las puertas del infierno (novela, de José Luis Díaz Granados), ambas con dos ediciones.

La baja cantidad de reediciones de los títulos de PE, tanto dentro de la editorial como en otras, se puede deber a dos razones: la primera de ellas, que el de PE es un catálogo vivo, pese a que ya no hay existencias de muchos títulos; la segunda, que se trata de obras que no son fácilmente aceptadas por otro tipo de editoriales y que quizá no se habrían publicado de no haber encontrado lugar en PE. La gran cantidad de títulos publicados por primera vez en PE da cuenta de la política editorial de los hermanos Pardo: abrir las puertas para la publicación de autores que difícilmente tienen acceso a otras editoriales o a medios económicos para publicar con sus propios recursos. El circuito editorial de los títulos reeditados sigue siendo el de las editoriales pequeñas, "alternativas" y también el de las universitarias (desde hace casi dos décadas); la única excepción es Grijalbo, que reedita Cóndores no entierran todos los días, una novela que ya es un clásico contemporáneo de la literatura colombiana.

Precisamente es el género novela el más reeditado, circunstancia que da cuenta del predominio de este género en el mercado editorial colombiano desde hace más de tres décadas. Quizás este mismo hecho haya llevado a que los hermanos Pardo, quienes en sus inicios se dedicaron al cuento, rápidamente hayan pasado a la novela y le hayan dedicado a este género la mayoría de su trabajo creativo. En este sentido, Jorge Eliécer Pardo es el escritor que más ha podido proyectar su obra y su imagen como escritor en el panorama literario colombiano, más allá de su publicación en PE; sin embargo, este ha sido un trabajo arduo, producto de la gestión continua del propio Jorge Eliécer.

Para los títulos que tuvieron su primera edición antes de su llegada a PE fue muy importante el papel jugado por Plaza \& Janés y por La Oveja Negra, ${ }^{8}$ pues 
muchos de estos títulos fueron publicados por estas dos editoriales (y por editoriales institucionales). En la segunda mitad de la década de 1970, La Oveja Negra y Plaza \& Janés (recién llegada a Colombia) deciden impulsar la publicación de obras literarias colombianas; la primera de ellas, sobre todo, con la colección Biblioteca de Literatura Colombiana (1984-1986), y la segunda con sus colecciones de escritores colombianos desde 1974 (Rotativa, Autores Colombianos) y hasta finales de la década de 1980. ${ }^{9}$ Plaza \& Janés, además, creó el Premio de Novela Colombiana en 1979 (con tirajes de 5000 ejemplares para Colombia), hecho que impulsó no solo a los autores colombianos dentro y fuera del país, sino también al género.

Los hermanos Pardo fueron muy cercanos a Virgilio Cuesta, director de Plaza \& Janés en Colombia, gracias a su amistad con Germán Vargas Cantillo, Fernando Soto Aparicio y Eduardo Pachón Padilla, asesores literarios de la editorial; Jorge Eliécer Pardo, Héctor Sánchez, Benhur Sánchez y Eutiquio Leal publicaron obras en esta editorial. Los tres primeros también lo hicieron en La Oveja Negra, junto a Carlos Orlando Pardo y Germán Santamaría. Tras el retiro de Virgilio Cuesta y su regreso a España, los escándalos por piratería de La Oveja Negra (la editorial colombiana más longeva, a la que le sigue PE) y el desinterés de las editoriales españolas por los escritores latinoamericanos a finales de la década de 1980, el último decenio del siglo xx en Colombia representa un declive mayúsculo en relación con las editoriales interesadas en publicar autores literarios colombianos con proyección internacional; en la segunda mitad, esta tarea fue asumida principalmente por Norma y luego por Alfaguara. En medio de este declive, editoriales como PE tomaron, de nuevo, la responsabilidad de brindarle al escritor (tolimense y) colombiano un lugar donde construir su trayectoria literaria.

\section{Editar desde la región en Colombia}

Las editoriales colombianas fundadas a finales de la década de 1970 y en la de 1980 transformaron el mercado editorial colombiano y ofrecieron un espacio para la

9 Por su parte, la llegada de Planeta al país será a mediados de la década de 1980, pero su catálogo estará más centrado en la publicación de no-ficción; de allí que sean Germán Arciniegas, Germán Castro Caycedo y Arturo Alape los autores colombianos con más títulos publicados hasta el año 2000.

En el catálogo de Plaza \& Janés, los autores con mayor cantidad de títulos publicados, entre la década de 1970 y el 2000, son Fernando Soto Aparicio y Gustavo Álvarez Gardeazábal. 
publicación de autores nacionales; a esto último contribuyó PE."Este momento de auge de la edición colombiana fue el resultado de una serie de factores: un mejoramiento en los aspectos legales, técnicos y económicos de la edición, y el fortalecimiento de una base lectora en el país" (Marín Colorado y Valencia, 2018, p. 197).

Como se puede apreciar, en este artículo he querido mostrar lo difícil que resulta romper las relaciones de poder que ejerce la vida literaria capitalina sobre la construcción de los prestigios literarios de los escritores colombianos y la necesidad de que los medios de comunicación de cobertura nacional y regional abran más espacios para visibilizar las obras de escritores que no necesariamente pueden publicar en las grandes editoriales multinacionales y corporativas o que no cuentan con un capital cultural o con un capital social sobresaliente. El trabajo realizado por las editoriales pequeñas o "alternativas", como se autodenomina PE, es absolutamente necesario para diversificar el campo editorial y el campo literario, pero todavía falta mucho trabajo para desmitificar el prejuicio flotante entre los lectores y demás agentes de dicho campo acerca de que aquello que se publica en editoriales regionales, pequeñas o "alternativas" no tiene el mismo valor literario de lo que se publica en las editoriales capitalinas, profesionales o corporativas.

Ante estas dificultades, la autogestión se convierte en una alternativa absolutamente lógica y necesaria, como lo demuestra la trayectoria de PE: la creación de grupos, de asociaciones y de editoriales, sostenida en fuertes redes de sociabilidad, para las que el circuito escolar y algunos sectores de la academia literaria se convierten en verdaderos aliados. Ante las formas de dominación en los campos editorial y literario, afortunadamente, siempre aparecen maneras de resistir, de no rendirse.

\section{Referencias bibliográficas}

Arango, J. I. (1991). El libro en Colombia. Situación y perspectivas. Bogotá: cerLALC. Casanova, P. (2001). La república mundial de las letras. Barcelona: Anagrama.

Dubois, J. (2014). La institución de la literatura. Medellín: Universidad de Antioquia.

Gómez García,J. G. (2005). Cultura intelectual de resistencia. Contribución a la historia del "libro de izquierda" en Medellin en los años setenta. Bogotá: Ediciones Desde Abajo-Universidad de Antioquia. 
Marín Colorado, P. A. (2018). Edición en Colombia (1970-1990): del boom de la industria gráfica a la diversificación de la industria editorial. En D. Guzmán et al. (Eds.). Lectores, editores y cultura impresa en Colombia. Siglos XVI-XXI (pp. 384-410). Bogotá: CERLALCUniversidad Jorge Tadeo Lozano.

Marín Colorado, P. A. y Valencia, M. (2018). El cuento y la literatura infantil en el catálogo de Carlos Valencia Editores (1975-1991): una editorial colombiana para colombianos. Badebec 15, pp. 167-202.

Ortiz Vidales, D. (1989). José María Melo: Razón de un rebelde. Pijao. De Arte y Literatura 2, p. 25.

Pardo, C. O. (2018). Entrevista con Paula Andrea Marín Colorado. Ibagué. Audio.

Pardo, J. E. (2018). Entrevista con Paula Andrea Marín Colorado. Bogotá. Audio.

Pijao. De Arte y Literatura (1989). Pijao. De Arte y Literatura 2, p. 19.

Sapiro, G. (2016). La sociología de la literatura. Buenos Aires: Fondo de Cultura Económica.

Silva, R. (2012). República Liberal, intelectuales y cultura popular. Medellín: La Carreta.

Tirado Mejía,Á. (1983). Algunas características regionales de Colombia. En Descentralización y centralismo en Colombia (pp. 41-59). Bogotá: Oveja Negra.

Torres Duque, Ó. (1990). Letras y glorias inmarcesibles. Boletín Cultural y Bibliográfico 27 (23), pp. 103-110. Recuperado de https://bit.ly/35iSPsD [15.08.2019].

Vargas Cantillo, G. (1976). Prólogo. En VVAA. La violencia diez veces contada (pp. 8-18). Ibagué: Pijao Editores. 